\title{
AS OCUPAÇÕES DOS ESPAÇOS PÚBLICOS À LUZ DE WALTER BENJAMIN E CHANTAL MOUFFE
}

\section{THE OCCUPATION OF PUBLIC SPACES IN LIGHT OF WALTER BENJAMIN E CHANTAL MOUFFE}

\author{
Lívia de Meira Lima Paiva ${ }^{1}$ \\ José Antônio Rego Magalhães ${ }^{2}$
}

\section{RESUMO}

Esse artigo pretende uma reflexão sobre as ocupações dos espaços públicos por parte de diversos atores da sociedade civil insatisfeitos com o poder público. Primeiramente apresentaremos o contexto de algumas ocupações como as dos colégios estaduais, das sedes do Ministério da Cultura, por artistas e do Ministério da Saúde por trabalhadores do setor para observar qual o tratamento jurídico dado a cada um dos casos a partir das ações de reintegração de posse. Em seguida, apresentaremos algumas leituras possíveis destes eventos à luz de Walter Benjamin em "Para uma crítica da violência" e de Chantal Mouffe em "O paradoxo democrático".

Palavras-chave: ocupações, espaços públicos, democracia, Walter Benjamin, Chantal Mouffe

\begin{abstract}
This article aims to reflect on the occupations of public spaces by many civil society actors dissatisfied with the government. In the first part we will present the context of some occupations as those of state schools, the Ministry of Culture buildings, by groups of artists and the Ministry of Health, by some groups of health professionals with a view to the legal treatment given in each case from the repossession's actions. Then, we present some possible interpretations of these events through Walter Benjamin's concepts in "Critique of Violence" and Chantal Mouffe's "The democratic paradox".
\end{abstract}

Keywords: occupations, public spaces, democracy, Walter Benjamin, Chantal Mouffe.

\footnotetext{
1 doutoranda em "Teorias Jurídicas Contemporâneas" no Programa de Pós-Graduação em Direito pela Universidade Federal do Rio de Janeiro - UFRJ, Rio de Janeiro (Brasil). Professora substituta de Teoria do Direito na UFRJ. E-mail: liviapaiva@globo.com

${ }^{2}$ Doutorando em direito na Pontifícia Universidade Católica do Rio de Janeiro (PUC-RIO). Mestre em "teorias jurídicas contemporâneas" na Universidade Federal do Rio de Janeiro.
} 


\section{INTRODUÇÃO}

Entre 2015 e 2016 diversos atores da sociedade civil promoveram ocupações dos espaços públicos como forma de protesto. Estudantes, artistas, profissionais da saúde, professores e outros atores participaram dessas ocupações que têm se tornado uma prática cada vez mais comum de produção política. Esses espaços de resistência surgem diante de uma crise da relação entre sociedade civil e poder público, onde o objeto não é a inversão da posse do imóvel, mas o uso político das instalações do Estado. As ocupações pacíficas podem ser analisadas como novas formas de produção de subjetividade e performatividade, e merecem especial atenção para a tutela jurídica dos direitos ali reivindicados, que muitas vezes não são direitos "já existentes", mas sim "novos direitos" que se tornam inteligíveis e exigíveis justamente a partir desses processos de subjetivação em desenvolvimento

Este artigo pretende apresentar três movimentos recentes de ocupação de espaços públicos. Em primeiro lugar, a ocupação de escolas estaduais, que a princípio tinham uma pauta específica, contra a reorganização do sistema de ensino, em São Paulo, mas que se tornou um movimento nacional pela melhoria das condições nas escolas. Em segundo e terceiro, a ocupação das sedes do Ministério da Cultura e do Ministério da Saúde em todo o país, por grupos de artistas e profissionais da área da saúde. Todos os eventos guardam características muito semelhantes em relação ao poder público, não obstante tenham tido tratamento judicial diferenciado.

Há, a partir da análise das ações de reintegração de posse de alguns juízos (estadual fazendário e federal), um tratamento heterogêneo para os ocupantes que ora figuram como manifestantes no exercício de um direito legítimo, ora como invasores que devem ser retirados o mais rápido possível dos imóveis públicos. Apresentaremos alguns aspectos dessas decisões judiciais. No entanto, a finalidade desse artigo é fornecer alguns conceitos da filosofia do direito e da ciência política que sustente uma das possíveis leituras desses eventos.

Não se pretende, portanto, a discussão de aspectos dogmáticos acerca da desobediência civil ou do direito de manifestação, mas promover uma reflexão à luz da filosofia do direito e da ciência política que possam alicerçar essas práticas dentro de um Estado Democrático de Direito. Para isso, utilizaremos o ensaio "Para uma crítica da Violência" (Zur Kritik der Gewalt) de Walter Benjamin onde o autor reflete sobre a violência do direito e expõe alguns conceitos 
como o de "meio puro", em torno do qual se desenvolve este estudo. Benjamin procura um pensamento capaz de romper o avançar contínuo da história e das formas opressoras do direito e propõe uma reflexão sobre o que seria uma manifestação que - de forma violenta ou não pudesse romper com esse ciclo.

Chantal Mouffe, por sua vez, é adotada aqui na medida em que questiona a capacidade do modelo democrático dominante nos países ocidentais de responder às demandas plurais da sociedade contemporânea. A autora mostra como a democracia liberal, caracterizada pelo racionalismo, individualismo e universalismo abstrato é fundada em uma ideia de consenso e de "inimigo" que muitas vezes excluem diversos posicionamentos para se alcançar "o meio termo" do que se pretende. A política de representatividade, para a autora, desencoraja a participação efetiva dos cidadãos na democracia, que longe de ser um regime de harmonia e transparência, é um espaço de dissenso.

1. O ciclo de ocupações de espaços públicos

Nesta seção, analisaremos primeiramente o movimento de ocupação de escolas de ensino médio desencadeado em São Paulo, para em seguida passar às ocupações relacionadas aos ministérios da cultura e da saúde.

\subsection{O movimento dos secundaristas}

Em novembro de 2015, em reação ao plano de reorganização das escolas da rede pública anunciado pelo governo do Estado de São Paulo, estudantes, pais e professores ocuparam algumas unidades, alegando falta de diálogo, ausência de justificativas pedagógicas e solicitando a suspensão da reorganização.

Com o lema "não fechem a minha escola", a primeira unidade a ser ocupada foi a Escola Estadual Diadema no ABC, no dia 9 de novembro, seguida pela Fernão Dias, em Pinheiros. Ainda no início do processo, a Fazenda Pública do Estado de São Paulo protocolou uma ação de reintegração de posse com pedido liminar que, embora inicialmente concedido à administração pública, foi suspenso pelo mesmo juízo. Na decisão, uma semana após a primeira ocupação, o magistrado Luis Felipe Ferrari Bedendi da $5^{\mathrm{a}}$ Vara de Fazenda Pública alega que 
mudou de ideia quanto ao pedido liminar quando tomou ciência da real situação da ocupação, "com um panorama mais amplo e real, não tão estritamente apegado à frieza do processo". 3

$\mathrm{Na}$ revisão da decisão ressalta-se o caráter "eminentemente protestante" (sic) do movimento, sem o animus de "inversão da posse", sendo descabido, portanto, a tutela judicial para o conflito. O magistrado afirma que se trata de uma "questão pública" cuja melhor solução encontra-se no diálogo do poder público com a população. Além disso, uma reintegração de posse pontual não faria com que outras escolas deixassem de ser ocupadas, pois o ciclo continuaria se repetindo, inclusive com uma possível reocupação da mesma escola desocupada com uso da força pela reintegração de posse.

A decisão é relevante porque nega a solução judicial para o caso, já que "não promoverá a solução do caso concreto, com a pacificação social”. Ela devolve o impasse para a sociedade. O poder público, assim, afirma a eficácia limitada de uma decisão judicial diante do problema. E, ainda que indiretamente, ao negar a pretensão estatal, reconhece as ocupações como um movimento legítimo para alcançar novas esferas de diálogo com o poder público. ${ }^{4} \mathrm{O}$ direito reconhece que nem toda a vida democrática se dá segundo suas normas, mas muitas vezes em espaços foras delas, a partir dos quais elas podem ser transformadas.

Menos de um mês depois, mais de 200 unidades já estavam ocupadas, de acordo com a Secretaria de Educação. As ocupações caminhavam na contramão da visão de escola pública conhecida pelo sucateamento, violência, desinteresse e desmotivação dos alunos. Essas imagens deram lugar a outras, opostas. Pelas redes sociais das ocupações, atualizadas diariamente pelos ocupantes, imagens de alunos pintando paredes, faxinando e cozinhando uns para os outros evidenciavam uma relação diferente da anterior.

A forte repressão policial também era registrada e publicada quase que diariamente, já que, além da ocupação da unidade, eram organizadas manifestações nas ruas, muitas vezes

\footnotetext{
${ }^{3}$ Da decisão, proferida no dia 13/11/2015 nos autos do processo 1045195-07.2015.8.26.0053 podemos destacar a seguinte passagem: "Contudo, este magistrado tomou contato, ao longo desta tarde de sexta-feira, na feliz reunião designada pelo Juiz Corregedor da Central de Mandados e pelas manifestações ulteriores juntadas aos autos, com um panorama mais amplo e real, não tão estritamente apegado à frieza do processo".

${ }^{4}$ Destacamos um outro trecho da decisão: "Com isso quero dizer que o cerne desta lide possessória não é a proteção da posse, mas uma questão de política pública, funcionando as ordens de reintegração como a proteção jurisdicional de uma decisão estatal que, em tese, haveria de melhor ser discutida com a população. Repito: objetivamente, tem-se esbulho de um bem público; mas a solução da questão foge, e muito, da simples tutela possessória. A questão é mais ampla e profunda, a merecer melhor atenção do Executivo. Há, ainda, um outro problema: caso mantidas as ordens, há a chance de se tornarem inócuos os comandos jurisdicionais futuros. A cada dia, uma nova escola pode ser invadida; expede-se, na sequência, a reintegração de posse, é ela cumprida e o ciclo se repete, com a possibilidade, inclusive, de existir a reocupação de uma escola já liberada".
} 
concomitantemente, para dar visibilidade à causa. Um gesto frequente nesses eventos era o bloqueio de avenidas pelos estudantes com cadeiras das salas de aula que não menos frequentemente eram dispersados pela polícia militar de forma truculenta. ${ }^{5}$

Inspirados pelas ocupações em São Paulo, estudantes da rede estadual do Rio de Janeiro ocuparam algumas unidades no início do ano de 2016. Embora não houvesse uma causa clara como a reorganização do sistema de ensino, as escolas no Rio foram ocupadas em apoio à greve dos professores da rede estadual por melhorias no sistema de ensino.

\subsection{A ocupação do Ministério da Cultura no Rio de Janeiro}

Em movimento semelhante, após a notícia da extinção do Ministério da Cultura ${ }^{6}$ pelo governo interino que assumiu a presidência da República em 16 de maio de 2016, um grupo de artistas, em protesto, ocupou um dos principais aparelhos culturais da cidade: o Palácio Gustavo Capanema, sede do MinC no Rio, onde funcionam o IPHAN, a FUNARTE e a biblioteca do MEC que contava com uma grande área inutilizada.

Dois dias após a ocupação, Marcelo Calero, então secretário de cultura do Rio de Janeiro foi empossado no cargo de secretário nacional de cultura. Na cerimônia de posse, ao ser perguntado sobre como o governo procederia com a ocupação nacional dos aparelhos de cultura, o ministro reconheceu a importância da ocupação, a legitimidade e o caráter democrático do movimento no palácio Capanema. ${ }^{7}$

Desde o início diversos coletivos e artistas independentes, apoiados por estudantes, profissionais de outras categorias como professores, jornalistas, filósofos e alguns funcionários

\footnotetext{
${ }^{5}$ Em um dos atos, pelo menos 28 estudantes foram detidos pela Polícia Militar. Disponível em: http://g1.globo.com/sao-paulo/noticia/2015/12/estudantes-fecham-vias-do-centro-de-sao-paulo-durantemanifestacoes.html Acesso 15 de ago. de 2016

${ }^{6} \mathrm{O}$ Ministério da Cultura foi extinto pela medida provisória $\mathrm{n}^{\circ} 726$ de 12 de maio de 2016.

7 "Repórter (Leandro Prazeres) - Como o senhor pretende lidar com as ocupações que foram feitas em repartições do IPHAN, FUNARTE (...)? MARCELO CALERO - Em relação as ocupações, a gente vai lidar com elas da maneira mais progressista e democrática possível no sentido de que se trata claro de espaços públicos. Hoje o senador Cristovam Buarque deu uma entrevista muito lúcida a respeito das ocupações na escola. E ele dizia que são movimentos sim legítimos, que não podem ser aparelhados. Eu acho que essa grande pedra de toque que a gente tem aqui em relação a esses movimentos. Eu acho muito bonito ver o pilotis do Palácio Capanema, que sempre foi um lugar meio asséptico meio frio... e hoje ele vivo, as pessoas interagindo, defendendo as suas causas. Isso é democracia. Isso tem que acontecer. É um espaço público. Claro que a gente não pode com isso, que isso se faça em detrimento das atividades desses órgãos. Isso realmente atrapalharia inclusive a operação, mas o caminho é reforçar os canais de diálogo e a democracia. " Disponível em: <https://www.youtube.com/watch?v=fV88yeXb9oU > Minutagem: 39:50. Acesso em 30 de jul. de 2016.
} 
do Capanema ocuparam o segundo andar, o mezanino e o pilotis do Palácio, áreas sem qualquer circulação de funcionários ou atividades executivas do Ministério da Cultura. A ocupação se manteve por meio de doações de muitos indivíduos e alguns sindicatos, associações e outros movimentos afetos à causa.

Com a anuência e aclamação de todos, um manifesto foi escrito "contra a extinção do MinC" e pela "saída imediata do governo ilegítimo de Michel Temer". ${ }^{8}$ Cinco dias após a ocupação, o presidente interino recria a pasta do Ministério da Cultura para acalmar os ânimos. Uma pequena parte do movimento representada pela APTR (Associação dos Produtores de Teatro) saiu então da ocupação, satisfeita com a volta do Ministério.

No entanto, a ampla maioria resistiu e paralelamente a expressão "não é só pelos 20 centavos" que ficou conhecida durante as jornadas de junho de 2013, cria-se o "não é só pelo fim do MinC". Durante a ocupação do Capanema uma programação cultural diária diversificada permitiu a circulação de artistas independentes e grupos, com shows, performances, espetáculos de circo, teatro e dança, dando utilidade social ao prédio. A programação não se restringiu à cultura, pautou aulas abertas, workshops e encontros com os mais diferentes temas envolvendo direito, sociologia, antropologia, ciência política, filosofia, entre muitos outros.

Um mês após o início da ocupação, a União ingressou uma ação com pedido liminar de reintegração de posse que, a princípio, em situação semelhante à ocupação dos secundaristas de São Paulo, é indeferido pela 20ª Vara Federal do Rio de Janeiro. No entanto, as duas negativas guardam profundas distinções: enquanto a primeira, do foro paulista, devolve a questão ao poder Executivo, para diálogo entre poder público e estudantes, a segunda sugere

\footnotetext{
${ }^{8}$ Sobre os objetivos e reinvindicações do movimento, conferir o "Manifesto Cultura pela democracia" do “\#ocupamincrj”, publicado na página de sua rede social e lido em assembleia no dia 20 de maio de 2016: "Faremos a governança real e simbólica na luta pelos nossos direitos, ocupando - de forma pacífica, mas contundente - o Palácio Gustavo Capanema sede do Ministério da Cultura do Rio de Janeiro. Reafirmamos que o espaço público é o lugar da luta política e que as ocupações são legítimas e necessárias. A extinção do Ministério da Cultura significa e simboliza não só a perda dos direitos dos trabalhadores da Cultura, conquistados em uma longa história de lutas e desafios, mas também a perda dos direitos de cidadania do povo brasileiro, garantidos pela Constituição de 88. E além das perdas do patrimônio material e imaterial da cultura brasileira, essa arbitrariedade representa um retrocesso histórico diante de um legado deixado por agentes culturais, individuais e coletivos, em seus diferentes campos de criação. No entanto, não se trata somente de garantir a sobrevivência de um setor. Esta ocupação da Cultura pela Democracia no Capanema é, sobretudo, pelo fim do governo ilegítimo de Michel Temer. Não aceitamos negociar com os coronéis do século XXI.” Disponível em: https://www.facebook.com/OcupaMincRJ/photos/a.574744092730872.1073741828.574736662731615/5763194 65906668/?type $=3 \&$ theater Acesso em 20 ago. 2016
} 
que o uso da força "pode e deve" ser exercido pela União, detentora legítima do poder de polícia quanto à posse do imóvel, de acordo com o artigo 144 (e seguintes) da Constituição Federal. ${ }^{9}$

Dez dias depois da decisão supracitada, no dia 25 de julho de 2016 a polícia federal invade o Palácio para liberar o imóvel e expulsar os ocupantes, que passaram a ocupar os jardins por mais dois dias. Para evitar que o imóvel fosse reocupado, a administração pública constrói um muro, impedindo o acesso às dependências do Palácio por parte não só dos ocupantes, mas de quaisquer outros cidadãos. ${ }^{10}$

\subsection{A ocupação do Ministério da Saúde no Rio de Janeiro}

Antes disso, porém, trabalhadores da saúde ocupam a sede do Ministério da Saúde por todo Brasil. No Rio de Janeiro o movimento, embalado pela série de ocupações, ${ }^{11}$ começou em 8 de junho de 2016 no Núcleo Estadual do Rio de Janeiro (NERJ) do Ministério da Saúde. A pauta era a possível extinção do Sistema Único de Saúde (SUS), ameaçado por uma proposta de "plano de saúde popular". De acordo com o movimento, que permaneceu 20 dias dentro da sede do Ministério da Saúde a luta era em "defesa da Saúde Pública como direito universal, com serviços gratuitos e de qualidade". ${ }^{12}$

\footnotetext{
${ }^{9}$ De acordo com a decisão: "É óbvio que qualquer reunião ou manifestação que aniquile por completo outros direitos também constitucionais, como a locomoção e a integridade física (no caso, dos próprios manifestantes e dos servidores que trabalham no prédio), bem como do patrimônio público, pode e deve ser evitada ou reprimida pelas forças de segurança do Estado, policiais ou militares. Ocorre que, para isso, o Estado - no caso concreto, o IPHAN -, entidade da União, não precisa se valer do Poder Judiciário para agir, seja preventiva, seja repressivamente. Pela sua própria natureza e pela autorização que lhe é dada pela CR/1988 (artigo 144 e seguintes), a União, entidade que abarca a autarquia federal, pode e deve agir com o uso de forças policiais sem que haja, para tanto, prévia autorização judicial. O que se nota na presente ação é o Poder Executivo Federal querendo transferir responsabilidade que é sua para o Poder Judiciário". RIO DE JANEIRO. JUSTIÇA FEDERAL. Reintegração/Manutenção da Posse, Processo no 0094506-37.2016.4.02.5101. AUTOR: IPHANINSTITUTO DO PATRIMONIO HISTORICO E ARTISTICO NACIONAL, RÉU: NÃO IDENTIFICADO. Autuado em 15/07/2016.

${ }^{10}$ Ressaltamos que até a data de publicação deste artigo o muro feito de tapumes permanece no Palácio, impedindo o livre acesso dos cidadãos a uma das principais obras arquitetônicas da cidade.

${ }^{11}$ Em sua rede social, principal forma de comunicação do movimento, o "\#ocupasusrj" manifesta a desocupação do prédio na "NOTA DO OCUPASUS RJ SOBRE A SAÍDA DO PRÉDIO DO NERJ", onde reconhece outras ocupações como inspiração para o movimento: "A ocupação é um meio de luta legítimo ao qual não renunciamos, e que vem sendo empregado de maneira vitoriosa e inspiradora no Brasil, seja com os estudantes secundaristas, o movimento de cultura, os Sem Terra e o Sem Teto". Disponível em https://www.facebook.com/ocupasusrj/posts/688400224641489:0 Acesso em 20 ago. 2016. Também disponível em http://www.contraprivatizacao.com.br/2016/06/1039.html Acesso em 20 ago. 2016.

${ }^{12}$ Op. Cit.
} 
A decisão liminar de reintegração de posse do NERJ proferida pela $29^{\mathrm{a}}$ vara federal (no processo $\mathrm{n}^{\circ}$ 0083670-05.2016.4.02.5101) ${ }^{13}$ reconhece o caráter pacífico da ocupação, mas o interpreta como um "exercício do direito de livre reunião e manifestação", que não pode ser feito de maneira abusiva, fato que, de acordo com a decisão, não vinha sendo observado, pois as reuniões no térreo do imóvel se davam "sem qualquer autorização da administração do prédio, prejudicando o acesso e tráfego de pessoas e servidores pelo local”. Por fim, a decisão afirma a proporcionalidade da medida de reintegração já que "os direitos titularizados pela autora, no presente caso, devem ser tutelados no seu todo, eis que isso não significará frustração do evento, que poderá ser realizado em qualquer outro lugar que não o interior do imóvel".

Os três casos apresentados acima possuem em comum o ato de ocupar um imóvel público como sinal de reprovação a atitudes do Poder Executivo. A resposta do judiciário, no entanto, é desigual, considerando por vezes os ocupantes como "estudantes", "crianças e adolescentes" ou "menores de idade" que buscam "maior participação da comunidade no processo decisório da gestão escolar" (como no caso da ocupação dos colégios em São Paulo) ou como "invasores" (como no caso do "\#ocupamincrj") ou ainda como manifestantes que visam exercer seu direito constitucional de reunião (como no caso do "\#ocupasus"). Há uma evidente confusão sobre qual o tratamento dar para cada situação que varia do reconhecimento de um direito "razoável” que está em exigência até a sugestão do uso da força para a desocupação.

Pela análise das decisões judiciais, percebemos que há uma dificuldade de estabelecer qual seria o polo passivo da lide, que no caso das ocupações das escolas foi ocupado pela APEOESP (Associação dos Professores Estaduais Oficial do Estado de São Paulo), na ação do MinC foi designado "Réu não identificado" e na ação do Ministério da Saúde foi ocupado pela CUT (Central Única dos Trabalhadores).

Analisado, ainda que rapidamente, o contexto das ocupações, e alguns aspectos das decisões judiciais, verificamos a ausência de uma resposta uniforme do direito para a questão. Isso parece dever-se, em parte, à maneira como a ocupação política dos espaços públicos não opera puramente a partir do reconhecimento anterior de um direito pelo sistema jurídico, mas sim a partir da projeção de um direito por vir, fruto do próprio processo de subjetivação política que tem lugar na ocupação. A fim de evitar uma análise excessivamente formalista o legalista

${ }^{13}$ Cf. RIO DE JANEIRO. Justiça Federal. Reintegração/Manutenção da Posse n 0083670-05.2016.4.02.5101. AUTOR: UNIAO FEDERAL (ADVOCACIA GERAL DA UNIAO), RÉU: CENTRAL ÚNICA DOS TRABALHADORES DO RIO DE JANEIRO - CUT E OUTROS. Autuado em 21/06/2016 
da relação entre as ocupações e o direito posto, que faria dela menos uma relação do que uma determinação unilateral, passaremos a uma discussão voltada mais à filosofia e à ciência política do que propriamente à análise "interna" do direito enquanto tal, especialmente a partir de alguns conceitos de Walter Benjamin e Chantal Mouffe.

2. A violência do direito e a noção de "puro meio" em Walter Benjamin

Benjamin, em seus estudos sobre violência, introduz esse conceito através da palavra alemã "Gewalt" significando também "poder" ou "autoridade" para problematizá-lo. A violência que instaura o direito, a que o mantém e a revolucionária são objeto do ensaio "Para uma crítica da violência” (Zur Kritik der Gewalt) de 1921 e, segundo Benjamin (2011), só podem ser analisadas na sua relação ética com o direito e a justiça. Longe de um sentido unívoco, a violência para Benjamin pode ser tanto interna como externa ao direito. ${ }^{14}$

Todo o direito é fundado em uma violência que o constitui e em outra que o mantém constituído fazendo-se passar por destino, ao qual seria justificável opor um poder divino ou uma justiça de fato. Nas palavras de Benjamin (2011, p. 146), "quem decide sobre a justificação dos meios e a justeza dos fins nunca é a razão, mas, quanto à primeira, a violência pertencente ao destino, e, quanto à segunda, Deus". A violência mítica se origina da "mera manifestação" ou "mera força" de um poder (Macht) que historicamente se constitui como legítimo, porém de forma circular. É, portanto, legitimado por esta primeira violência que o instaura, mas a partir daí esta apenas manifesta-se - como os deuses manifestam suas vontades - de forma imediata, instituindo os próprios fins aos quais se dirige.

À violência mítica do direito, Benjamin opõe a violência divina como "puro meio", pois esta rompe com o "círculo atado magicamente nas formas míticas do direito" (BENJAMIN, 2011, p. 155). O autor utiliza a greve dos trabalhadores como exemplo de uma violência revolucionária que, embora constitua uma simples abstenção não-violenta, não deixa de ser uma violência para o direito vigente. "A greve geral não acontece com a disposição de retomar o trabalho depois de concessões superficiais (...), mas com a resolução de retornar ao trabalho totalmente transformado, sem coerção por parte do Estado" (BENJAMIN, 2011, p.143).

\footnotetext{
${ }^{14}$ Faz-se aqui uma contraposição a Carl Schmitt cuja teoria defende que a esfera do direito captura toda violência - e se preocupa necessariamente com a relação entre fins a serem alcançados e os meios utilizados para atingir esses fins.
} 
Há, no entanto, uma diferença entre a greve dos trabalhadores, aquela prevista e regulamentada pelo direito, de uma greve revolucionária. Esta última é vista com hostilidade pelo Direito pois foge à sua regulação. Por mais passiva que seja, é considerada violenta. A greve não-revolucionária não oferece perigo à manutenção da ordenação do Direito porque está circunscrita dentro de seu domínio.

O direito moderno retira dos sujeitos a violência capaz de estabelecer um novo direito. No entanto, Benjamin apresenta algumas situações em que o Estado é obrigado a reconhecer forças que instauram direitos por meio da violência para obter determinados fins "naturais". 15 Assim como o direito de guerra, o direito de greve é uma violência sancionada pelos sujeitos capaz de fundamentar e modificar relações de direitos.

Como práticas de violência, o Direito limita sua abrangência: ao admitir formalmente esses dois direitos, as duas violências que instauram novos direitos são circunscritas no domínio normativo. As ações violentas de operários que quebram máquinas, ateiam fogo às fábricas são substituídas por uma previsão legal do direito de greve, a princípio contraditório aos interesses do Estado, mas considerado um mal menor do que as ações violentas. Para não enfrentar as ações violentas e garantir a ordem, o Estado reconhece um direito.

Uma leitura semelhante à de Benjamin em relação ao direito de greve pode ser feita à ocupação das sedes do Ministério da Cultura em todo o país. No dia seguinte ao afastamento da ex-presidente Dilma Rousseff, a extinção do Ministério por medida provisória (726/2016), transformando-o em uma secretaria ligada ao Ministério da Educação, fez com que, em uma reação em massa, milhares de artistas ocupassem os aparelhos culturais ligados ao Ministério da Cultura exigindo a deposição do governo. Após uma semana e a adesão de grande parte da sociedade civil ao movimento "\#ocupaminc" o governo interino voltou atrás e recriou a pasta como um ministério independente. De acordo com Mendonça Filho, ministro da educação, a recriação do Ministério da Cultura se deu para "serenar os ânimos", como tentativa de conciliação para encerrar uma "guerra política" que se estendeu à cultura. ${ }^{16}$

\footnotetext{
15 Aos "fins naturais" Benjamin opõe os "fins de direito". A obrigação do serviço militar (assim como a polícia) é um exemplo de fim de direito, uma violência que tem como função não mais a instauração, mas a manutenção do direito.

${ }^{16} \mathrm{O}$ ministro se manifestou em rede social no seguinte sentido: "A decisão de recriar o Minc é um gesto do presidente Temer no sentido de serenar os ânimos e focar no objetivo maior: a cultura brasileira. [...] Com Marcelo Calero vamos trabalhar em parceria para potencializar os projetos e ações entre os ministérios da Educação e da cultura". Disponível em: http://g1.globo.com/politica/noticia/2016/05/temer-decide-recriar-ministerio-da-cultura-anuncio-deve-ser-naterca.html Acesso em 20 de ago. 2016
} 
De volta à análise do "meio puro", Benjamin estabelece uma distinção entre a greve política, que só tem como finalidade a troca de quem detém o poder estatal, que passa "de privilegiados para privilegiados", e a greve proletária que tem como tarefa "aniquilar o poder do Estado" (BENJAMIN, 2011:142).

Giogio Agamben em "Estado de exceção" faz uma leitura do ensaio de Benjamin.

A tese de Benjamin é que enquanto a violência mítico-jurídica é sempre um meio relativo a um fim, a violência pura nunca é simplesmente um meio legítimo ou ilegítimo - relativo a um fim (justo ou injusto). A crítica da violência não avalia em relação aos fins que ela persegue como meio, mas busca seu critério "numa distinção na própria esfera dos meios, sem preocupação quanto aos fins que eles perseguem” (AGAMBEN, 2004, p. 95).

A violência enquanto meio puro não se preocupa com fins justos. A pureza não está na natureza da violência, mas na relação com os meios jurídicos. Ainda segundo Agamben (2004) "a violência pura expõe e corta o elo entre direito e violência que governa ou executa (die schaltende), mas como violência que simplesmente age e se manifesta (die waltende)". Essa relação exclusiva com a sua medialidade faz da violência divina uma manifestação imediata que se revela para encerrar/interromper uma violência instaurada e mantida.

Vejamos se não é o que acontece com as ocupações em questão. Os estudantes, descrentes e descontentes da atuação do Estado no ensino público, ao ocupar as escolas anulam a participação do deste no ensino. O Estado que, até então, era o responsável por conectar a instituição-escola ao indivíduo-aluno é retirado dessa função de poder. A escola passa a ter sua função social, até então responsabilidade do poder público, garantida pelos estudantes, que devolvem a ela seu papel de original de educação. Há o rompimento de um vínculo, a suspensão da incidência do poder do Estado, como forma de gerar um espaço em que as relações possam se estabelecer outramente - para que a política, em seu sentido estrito, possa se dar, não como mediação e representação, mas como ação e diálogo políticos.

Uma leitura semelhante pode ser feita em relação à ocupação do Palácio Gustavo Capanema. Ao ocuparem um espaço de cultura ocioso, os artistas não só devolvem ao espaço a sua função social, a cultura, mas também afirmam que farão "uma governança real e simbólica".

Há que se ressaltar, contudo, que o que se tem aqui por "função social" não é puramente uma função constitucionalmente definida, o que implicaria em uma captura dessa forma de ação política no ciclo do poder que funda e mantém o direito, mas justamente na 
subtração desse espaço do seu uso normativo, a fim de devolvê-lo a uma certa indeterminação do uso, que poderia ser chamada "social", mas apenas no sentido do social como tudo aquilo que excede às determinações jurídicas. $\mathrm{O}$ "social" como vida democrática sem moldes, que eventualmente intervém para suspender e questionar as próprias estruturas que determinam os limites do social e a função dos meios.

Durante as atividades culturais promovidas no Palácio Capanema, um documento intitulado "Ocupa tudo: manifesto por uma desobediência civil" foi produzido e distribuído a partir "da entrevista com 25 ocupantes do Ocupa Minc-RJ na primeira quinzena de 2016". A divisão é feita em 6 tópicos, pressupostos das ações da ocupação: "resistir", "re-significar", “conviver \& construir", “comunicar", "viralizar". Destacamos um trecho do documento que, após afirmar o afastamento do Ministério da Cultura dos próprios artistas por uma "gestão errada", protesta por uma cultura do povo: "ela [a cultura] é das comunidades e dos artistas populares que criam e compartilham. Ocupando, tomamos de volta o que nos pertence".

Em Benjamin, a greve revolucionária rompe com a violência mítica do direito, manifestando-se em uma interrupção da ordem vigente. As ocupações são manifestações que rompem com um ciclo de violência institucional. Para Benjamin (1986: 187), o gesto violento é dotado de um

caráter destrutivo [que] conhece apenas uma divisa: criar espaço; conhece apenas uma atividade: abrir caminho. Sua necessidade de ar puro e de espaço é mais forte do que qualquer ódio. (...) O caráter destrutivo não se fixa numa imagem ideal. Tem poucas necessidades, e a menos importante delas seria: saber o que ocupará o lugar onde se encontrava a coisa, onde vivia a vítima.

Também as ocupações, ao romperem com a violência mítica, abrem caminhos para novas produções de subjetividades: “a ocupação é mais do que um desrespeito. É uma revolução pacífica e cultural contra o sistema, uma desconstrução de paradigmas, um laboratório onde se experimentam outras formas de viver, trocando uma versão individualista por uma versão coletiva" (OCUPA MINC RJ, 2016:3).

Assim, aparece a sugestão de que as ocupações de espaços públicos, ao interromper o fluxo natural das coisas e possibilitar, dessa forma, um rompimento no contínuo da história, se aproxima da violência "divina" de Benjamin, no sentido de que nenhum dos dois põe nada propriamente, mas apenas interrompe, depõe, torna inoperantes os mecanismos do estado atual de coisas, sem determinar aquilo que virá a substituí-lo, mas apenas para abrir espaço para o advento de alguma coisa. Essa alguma coisa ainda está em aberto, mas será produto de formas 
outras de estar junto e de comunicar-se que se tornam possíveis - ou, a rigor, entram em uma zona de indistinção entre possibilidade e impossibilidade - sempre que a ordem instituída é momentaneamente suspensa.

Ocupar não é um meio para um fim, nem um fim em si mesmo. Um "puro meio", é algo que "manifesta-se a si mesmo" de forma imediata. A ocupação não se refere a nada além de si mesma e não representa nada além de si mesma. Ela quebra com a lógica do signo e da representação.

\begin{abstract}
A ocupação é uma construção política de uma democracia horizontal onde todo mundo tem voz. Entre erros e acertos, cada passo tem seus momentos críticos pedindo ajustes e cada debate gera tensões e transformações, deslocando vários pensamentos antes de chegar no consenso. A nossa força está no movimento. Nem no fim, nem no impulso, mas no caminho. A própria criação desses processos coletivos se torna uma estratégia para enfrentar o sistema. Somos executores. Somos um núcleo de ação e produção que descontrói pela prática o machismo, a homofobia, o racismo, a família tradicional o ego e a propriedade. (OCUPA MINC RJ, 2016:4) [grifo nosso]
\end{abstract}

Essa produção coletiva de novos formas de relação política e democrática nos leva à próxima seção, em que buscaremos um vocabulário a partir do qual pensar a democracia viva para além da sua identificação às atuais formas da representação democrática. Para tanto, o pensamento de Chantal Mouffe se mostrará interessante.

\title{
3. A democracia e o "pluralismo agonístico" de Chantal Mouffe
}

Em "The democratic paradox" Chantal Mouffe questiona a capacidade do modelo democrático dominante nos países ocidentais de responder às demandas de uma sociedade plural. A democracia liberal, caracterizada pelo racionalismo, pelo individualismo e pelo universalismo abstrato está fundada na ideia de consenso, que entende as diferenças como algo a ser superado em nome de uma racionalidade universal. Este modelo de democraciadeliberativa que, de acordo com Mouffe se desenvolve desde o século V a.C. na Grécia, tem como alicerce a ideia de que as decisões políticas "devem ser alcançadas por meio de um processo de deliberação entre cidadãos livres”. (MOUFFE, 2000:81)

A autora apresenta um novo modelo que emerge no século XX, o "modelo agregativo", condicionado à representação partidária que entende a democracia como "o sistema no qual as pessoas teriam a oportunidade de aceitar ou rejeitar seus líderes graças a um processo eleitoral competitivo" (MOUFFE, 2000:82). 
O "bem comum” seria substituído, então, por uma visão agregativa de valores plurais que através do consenso iria além dos meros procedimentos e atingiria a moral. O princípio da soberania popular restaria prejudicado por oferecer riscos aos valores liberais e, portanto, a participação popular é constantemente desencorajada e transferida para a representação em partidos políticos. Assim sendo, o maior ato político de um cidadão seria votar naquele que o representará no parlamento.

O insucesso do modelo é apontado pela autora pelo fato das democracias contemporâneas funcionarem "com uma concepção de sujeito que é anterior à sociedade”. Essa inversão, para autora, privilegia um ponto de vista individual e baseado no acordo, que satisfariam tanto a racionalidade (entendida como defesa de direitos liberais) quanto a legitimidade democrática (tomada como soberania popular). ${ }^{17}$

\begin{abstract}
Indivíduos da democracia só serão possíveis com a multiplicação de instituições, discursos, formas de vida que fomentem a identificação com valores democráticos. Eis a razão por que, apesar de concordar com os democratas deliberativos sobre a necessidade de um conceito diferente de democracia, vejo suas propostas como contraproducentes. Em rigor, precisamos formular uma alternativa ao modelo agregativo e à concepção instrumental da política que esse modelo fomenta. Está claro que ao desencorajarem o envolvimento ativo dos cidadãos no funcionamento da unidade política e ao encorajarem a privatização da vida, eles não asseguraram a estabilidade que anunciaram. Formas extremas de individualismo espalharam-se amplamente, ameaçando a própria "fábrica social" [the very social fabric]. (MOUFFE, 2000:96)
\end{abstract}

Se por um lado esse modelo, conforme a autora, funciona como desencorajador da participação política, por outro ele é o responsável pela identificação cada vez mais com a religião, com ideais fundamentalistas morais e étnicos. $\mathrm{O}$ afastamento da vida democrática é compensado pela identificação subjetiva em outros âmbitos. Como alternativa, Mouffe apresenta um modelo "agonístico" de democracia, que leva em consideração a natureza do político, inscrevendo a questão do poder e do antagonismo no seu próprio centro. (MOUFFE, 2000:99)

Essa ideia implica na desconstrução da sociedade democrática como sinônimo de harmonia. O poder não deve ser eliminado - o que, a final, seria uma impossibilidade - ou

\footnotetext{
${ }^{17}$ Charles Taylor também fornece uma crítica do atomismo individual que aliena a esfera pública. O autor utiliza Tocqueville sobre "o poder de tutelar" do Estado para refletir sobre a participação dos indivíduos na vida pública. Este depotismo suave se dá de forma centralizadora da política, por mecanismos impessoais que promovem a sensação da participação política, mas que, na prática é usurpada pelo poder de tutelar do Estado. Para mais, cfr. TAYLOR (2011).
} 
entendido como um ente externo, mas deve ser considerado como constitutivo das relações sociais. O modelo da autora pretende guardar as relações potencialmente antagônicas inerentes ao convívio social em todas as esferas da vida democrática.

A diferença entre antagonismo, próprio da democracia deliberativa, e "agonismo" é apontada pela autora pela distinção de inimigo e adversário: enquanto o primeiro tende a eliminar as questões pessoais do debate o público o segundo se constrói com base na expressão singular e no dissenso.

Uma abordagem "agonística" reconhece os limites reais de tais fronteiras e as formas de exclusão que delas decorrem, ao invés de tentar disfarçá-los sob o véu da racionalidade e da moralidade. Compreendendo a natureza hegemônica das relações sociais e identidades, nossa abordagem pode contribuir para subverter a sempre presente tentação existente nas sociedades democráticas de naturalizar suas fronteiras e "essencializar" as suas identidades. Por essa razão, ele é muito mais receptivo do que o modelo deliberativo à multiplicidade de vozes que as sociedades pluralistas contemporâneas abarcam e à complexidade de sua estrutura de poder. (MOUFFE, 200:105)

Passemos à análise das ocupações à luz desta concepção de democracia. Nelas, os espaços ocupados são inscritos em uma ordem de produção política sem nenhuma definição a priori. Os acordos e decisões políticas são realizados sem a instância da representatividade. As individualidades são consideradas como parte constituinte do processo, sem que o coletivo fique de lado. Cada sujeito possui toda a ocupação dentro de si, age por ela, fala por ela e se responsabiliza por ela. Por isso uma ocupação não pode se constituir enquanto movimento social (tal como temos tradicionalmente), pois teria que produzir um discurso bem determinado, introduzindo instâncias de representação ou lideranças, por exemplo, o que acarretaria a anulação ou exclusão de subjetividades ou na representatividade de uma "categoria" ou "grupo". Ao contrário, a indeterminação, pelo menos temporária, desse "nós" é constituinte do espaço da ocupação.

Analisando a ocupação do Ministério da Cultura no Rio de Janeiro a partir do documento "Ocupa tudo: manifesto para uma desobediência civil" é possível perceber a preocupação com essa dimensão participativa do sujeito. No segundo tópico os ocupantes, em sua grande maioria artistas, enfatizam o isolamento do Ministério da Cultura, apontando-o como um “órgão elitista, que não olha para os movimentos sociais e nega direitos das periferias" 
com "prédios míticos, ícones de um poder inacessível para quem não obedece a uma certa maneira de se vestir, de falar e de se ver."

Em seguida, propõe uma prática de convivência que substitua a representação dos interesses sociais na forma do Ministério - o que, afinal, sempre corre o risco de degenerar em não-representação - mas que garanta o pluralismo:

[a ocupação] é a convivência, num único espaço, de várias ideologias, culturas, peles, experiências, idades, pensamentos, origens, classes, forças políticas e movimentos sociais. Ela reúne pessoas que, às vezes nem se conheciam antes de ocupar junto. Dessa pluralidade (grifo deles) de falas, acaba nascendo uma comunidade que inventa novas formas de se relacionar. Um novo sistema onde a mudança começa consigo mesmo. Ocupar é resistir, transformar, criar e agir com processos sustentáveis, olhando um para o outro e valorizando nossas diferenças. A organização colaborativa empodera o coletivo e realiza o ser humano. Aqui, se aprende a escuta (grifo deles), o diálogo, a paciência, o respeito e a tolerância. Aqui, se constrói em conjunto, dividindo as atribuições e inserindo-se no processo. Aqui, se aposta na ideologia, na união, na autonomia e na ajuda mútua. Aqui, se discute política e arte, com colocar ninguém em patamar inacessível. (OCUPA MINC RJ, 2016:3)

A representatividade é anulada por sua ineficácia diante de um isolamento e não reconhecimento de algumas identidades culturais. Essa substituição se dá na vivência de um modelo de prática política que se descobre e altera o tempo todo pois não está fundado em nenhum dogma jurídico, código ou moral a priori. Sendo assim, tendemos a inferir que as ocupações, além de representarem uma interrupção no ciclo de violência do direito, fundam uma ordem democrática baseada na não-representatividade, na criatividade e no dissenso.

\section{CONCLUSÃO}

Ao longo deste artigo, procuramos apresentar o contexto de algumas das mais diversas ocupações de espaços públicos nos últimos dois anos. Apesar de guardarem algumas semelhanças em relação umas às outras, as ocupações recebem tratamento jurídico diferenciado, como inferimos das decisões judiciais trazidas. Há um tratamento heterogêneo dos ocupantes, que ora são considerados como "estudantes", "crianças e adolescentes" ou "menores de idade" que buscam "maior participação da comunidade no processo decisório da gestão escolar", ora como "invasores" e ora como manifestantes no exercício do seu direito constitucional de reunião. Essa falha do enquadramento jurídico de dar conta dos sujeitos dessas manifestações mostra-se compreensível, a partir do momento em que se observa as ocupações 
como deslocando-se em um espaço dúbio entre o exercício de um direito existente e a fundação de um novo direito - situação análoga à que Benjamin observa na sua "greve geral proletária".

De certo modo, o que se observa com a difusão de uma nova forma de participação política que se manifesta na ocupação dos espaços públicos poderia ser descrito como uma versão "micropolítica" dessa greve geral: a interrupção das relações de determinação normativa não se dão de uma forma geral e definitiva - à maneira da revolução compreendida em termos modernos -, mas de forma difusa, temporária e estratégica.

A partir dos conceitos trazidos por Benjamin, procuramos discutir as ocupações enquanto novos espaços de experimentação política. Não se trata da aferição de um conhecimento "sociológico" sobre o tema, de uma observação através da análise dos dados empíricos em jogo, mas da abertura de uma possibilidade de leitura a partir de um marco teórico que, em grande medida, questiona justamente a possibilidade da produção de conhecimento sobre esse tipo de prática.

Ocupar, no prisma exposto aqui, não é um meio para um fim, nem um fim em si mesmo, um "puro meio", é algo que "'manifesta-se a si mesmo de forma imediata". A ocupação não se refere a nada além de si mesma e não representa nada além de si mesma. Ela quebra com a lógica do signo e da representação. $\mathrm{Na}$ ocupação repetem-se os gestos cotidianos, mas de maneiras inteiramente outras às maneiras que cotidianas. Nela, todos os gestos são liberados do seu sentido normal: o gesto político é liberado do seu uso normal, como o gesto em geral o é na dança, e como a palavra o é na poesia (AGAMBEN, 2015).

Giorgio Agamben, recuperando o conceito benjaminiano de "puro meio" e relacionando-o ao gesto, afirma que "o gesto rompe a falsa alternativa entre fins e meios que paralisa a moral e apresenta meios que, como tais, se subtraem ao âmbito da medialidade, sem se tornarem, por isso, fins" (AGAMBEN, 2015:59). Para o autor, "o gesto é a exibição de uma medialidade, o tornar-se visível de um meio como tal. Ele faz aparecer o ser-em-um-meio do homem e, desse modo, abre-lhe a dimensão ética. Toda essa tematização do gesto como puro meio poderia inaugurar o estudo, no âmbito ainda indeterminado da ocupação política, da dinâmica da gestualidade - como todo o portar-se dos corpos, naquela cena, recupera a potência de dar-se o sentido, indeterminando a relação normal entre o gesto cotidiano e o seu significado.

A ocupação quebra, assim, com a linguagem da representação, palavra como signo que se refere a algo para além dele. E ela quebra com a política da representação no sentido da democracia representativa, devolvendo a política à participação direta dos sujeitos. É o que 
procuramos ler através do conceito de "democracia agonística", de Mouffe, na medida em que dá lugar ao pluralismo, no dissenso além de considerar a manifestação concreta e física do poder nas relações, absolutamente por fora das formas do direito. A força é liberada das formas do poder, podendo assim reconfigurar-se em novas tensões e resoluções.

Uma ocupação é um laboratório de política em que novas formas de vida e participação são inventadas. Ela é um espaço de produção de alternativas. Uma ocupação não fecha uma escola, ela faz uma escola verdadeira. Em uma ocupação, a própria linguagem em que se dá o diálogo está sempre aberta à negociação, e não há instituições para adjudicar as diferenças. Ocupar implica em desenvolver capacidades de gestão do espaço, de produção de bens e serviços vitais, de criação de redes de solidariedade, de atividade cultural e de instâncias democráticas de decisão. A ocupação recusa, em regra, toda razão transcendente à própria ocupação. A ocupação é imanente. Ocupar é, em primeiro lugar, dizer não, mas dentro deste não há a semente de um sim diferente. Ocupar é exercer poder destituinte e, talvez, poder constituinte, no local. As ocupações devolvem o poder constituinte ao povo, e o lembram que esse poder sempre foi dele.

A construção de subjetividades presente nas ocupações talvez sejam, assim, uma alternativa de prática política, pois abrem espaços novos, onde a solidariedade é construída, e novas atividades e trabalhos do comum são tornadas possíveis. Devido ao seu caráter criativo e instaurador de novas práticas, as ocupações são frequentemente "lidas" pelo direito a partir do repertório jurídico, ao invés de serem inseridas em sua dimensão propositiva. $\mathrm{O}$ desafio que se impõe ao pensamento, nesse quadro, é também o de abrir (ao invés de encerrar) entendimentos e proporcionar que essas novas práticas influenciem diferentes leituras e novos modelos democráticos. Menos, portanto, produzir conhecimento sobre o que efetivamente são ou foram as ocupações, do que garantir no discurso um espaço de indeterminação através do qual possa reluzir a potência criativa desses espaços em que os contornos do que está por vir começam, sutis, a delinear-se.

\section{REFERÊNCIAS}

AGAMBEN, Giorgio. Estado de Exceção. São Paulo: Boitempo, 2004.

Meios sem fim: Notas sobre a política. São Paulo: Autêntica, 2015.

BENJAMIN, Walter. Escritos sobre Mito e Linguagem. São Paulo: Editora 34, 2011. 
MOUFFE, Chantal. Democracia, cidadania e a questão do pluralismo. Versão em espanhol deste texto foi apresentada no II Seminário Internacional Educação Intercultural, Gênero e Movimentos Sociais: identidade, diferença e mediações, promovido pela Rede Rizoma e realizado em Florianópolis (SC), entre 8 e 11 de abril de 2003. A tradução, a partir da versão em inglês, foi feita por Kelly Prudencio, doutoranda do PPGSP/UFSC.

The democratic paradox. New York: Verso, 2000.

OCUPA MINC. Ocupa tudo: manifesto para uma desobediência civil. Mimeo

TAYLOR, Charles. “Ética da Autenticidade”. São Paulo: É Realizações, 2011. 